\begin{abstract}
Purpose: The objective of this research is to analyze the effect of corporate governance practices on firms' financial performance, as measured by comprehensive income.

Design/methodology/approach: Using a sample of 237 firms from the S\&P 500 Index during the years 2004 to 2009, multivariate statistical analyses are conducted in order to confirm our main hypothesis.

Findings: The results indicate that having high levels of corporate governance culture has a positive impact on a measure of firms' financial performance, namely comprehensive income. Furthermore, they indicate a positive correlation between the percentage of external directors and financial performance, and a negative relationship between number of board meetings and financial performance.
\end{abstract}

Originality/value: The main contribution of this research is that good corporate governance strategies deliver superior financial performance for businesses in terms of comprehensive income. This serves as a method of value creation, which is the ultimate goal of a business. In addition to the use of comprehensive income as an indicator of financial performance, a unique measure of corporate governance level is tested.

Keywords: Corporate governance; financial performance, board of directors, outside directors, duality, board meetings, CEO compensation, comprehensive income.

Paper type: Research paper 
Research interest in the concept of 'corporate governance' has grown considerably over the past decade (Calderón and Villabón, 2017), particularly as a result of recent economic crises. Some studies suggest that high levels of corporate governance may reduce managers' earnings manipulations and tendency to commit fraud; in addition, it may achieve a higher quality of information (Prior et al., 2008; Scholtens and Kang, 2012; Shi et al. 2017). Incidents of frauds are related to the boards of directors' decisions, which are seen as the instrument used by shareholders to monitor the behaviour of top managers (Fama and Jensen, 1983). However, actions intended to improve corporate governance have informationprocessing and opportunity costs for firms; the questions then become, do these strategies have a positive impact on companies' results, and do corporate governance strategies create value for companies? If the answers to these questions are 'yes', managers will need to invest in corporate governance. However, if the answers are 'no', managers will not need to develop corporate governance strategies.

The origins of corporate governance go back many years, to the time when ownership and management of businesses first became separated in accordance with the agency theory. However, measuring, for example, the true independence of a board director is difficult because of the subjectivity and intangibility of this concept (Abdo, 2007). There are two main approaches to minimizing agency problems: improving corporate governance structure (Baek et al., 2009; Cerbioni and Parbonetti, 2007; Patelli and Prencipe, 2007; Valenti et al., 2011) and promoting greater transparency of information (Fernández-Rodríguez et al., 2004; Price et al., 2011). However, when considering the implementation of these approaches, both strategies should have a positive impact on financial performance; otherwise, there will be unnecessary costs. Prior studies have explored the effects of corporate governance measures on firm performance, although empirical findings are mixed (Sami et al., 2011; Wang et al., 2016). One reason for these inconclusive findings could be the use of different approaches to measuring corporate governance: Some authors have used composite measures of corporate governance as indexes, while others have used individual corporate governance attributes, such as board characteristics or ownership structure (Jackling and Johl, 2009; Klappers and Love, 2004; Richart-Ramón et al., 2011). However, specific corporate governance mechanisms, such as the size and composition of boards and leverage and firm size, tend to mitigate the occurrence of agency costs in the USA (Garanina and Kaikova, 2016).

The objective of this paper is to investigate the impact of firms' corporate governance structures on their performance; this is done with the intention of reducing information asymmetry and assisting companies to achieve their central purpose, the creation of value. Using a sample of 237 companies (1,422 firm-year observations) listed on the Standards \& Poor 500 index during the period between 2004 and 2009, we hypothesize that having high levels of corporate governance culture will have a positive impact on firms' financial performance. The hypotheses are tested using general linear regression models. We develop our own index of corporate governance level, which takes into account the variables that have the greatest effect on the internal characteristics of boards of directors, in order to determine the corporate governance culture level of a company. Comprehensive income is more closely related to the fluctuation of share prices and exchange rates than traditional net income; thus, it is much more in accordance with the market reality (Arimany et al., 2011; Kanagaretnam et al., 2009).

Our main contribution is the evidence offered to support the notion that having a high level of corporate governance culture has a positive impact on a firm's financial performance. This finding serves as an incentive for managers to develop superior corporate governance strategies, as doing so will have a positive impact on a firm's profitability. In addition, the use of comprehensive income to measure accounting results could serve as a trustworthy broad indicator of the performance and corporate governance of a firm; it also takes into account not only economic profit but also the creation of value. To the best of our knowledge, no prior studies have used comprehensive income to measure firms' performance.

The paper proceeds as follows: In the following section, we present background research into corporate governance and the hypothesis. The third section provides an overview of the research design, including the details of the research sample and the methodology. Section four summarizes the findings; finally, we conclude this research by discussing its main implications and limitations. 


\section{CORPORATE GOVERNANCE AND FIRM PERFORMANCE}

From the agency theory perspective, guidelines for the relationships between managers and owners are warranted; they should protect shareholders' interests through implementing codes of good governance. The agency theory suggests that a better-governed firm should demonstrate superior performance due to lower agency costs (Rani et al., 2014; Sami et al., 2011). However, there is no consensus in the existing literature with regard to how corporate governance or performance outcomes should be measured. This topic is a central issue confronting corporate governance scholars, and there also remain intense areas of corporate governance research (Kumar and Zattoni, 2013). Many previous empirical studies, such as those of Gompers et al., (2003); Brown and Caylor, (2006, 2009); Dittmar and Mahrt-Smith (2007) and others, support this link. However, measuring corporate governance is difficult because it cannot be directly observed, and it usually involves multiple dimensions (Sami et al., 2011). A common approach to measuring corporate governance is to create an index. The corporate governance indexes that have been used previously have either been developed by the research teams in question or generated by commercial firms. Despite their limitations, studies that use commercial ratings do not differ significantly from those that use self-constructed indexes in terms of the evidence produced, although commercial rankings "are often too subjective and, therefore, might lead to an incorrect assessment of a firm's governance quality" (Bozec and Bozec 2012; p. 85). Additionally, one should take into account the different measures of financial performance (such as return on assets [ROA], return on equity [ROE], market value, Tobin's Q, etc.) when investigating the relationship between corporate governance and financial performance. This is why the relationship between corporate governance and financial performance is not clear; that is, a different way to measure for both variables. Some researchers obtained mixed results (Bebchuck et al., 2009; Bhagat and Bolton, 2008; Chidambaran et al., 2008; Core et al., 2006) or no evidence of any effect (Daines et al., 2010; Epps and Cereola, 2008; Diavatopoulos and Fodor, 2016; Johnson et al., 2009; Koehn and Veng, 2005; Lehn et al., 2007); however, the majority of researchers have identified a positive correlation between corporate governance indexes and firm performance in the US, which is the focus of the sample used in this research. For instance, Gompers et al. (2003) created the G-index, which uses 24 factors to measure corporate governance, including compensation plans, special meetings, voting and others. Their results indicate that, during the 1990s, better-governed US firms demonstrated higher operating performances (in terms of net profit margins and sales growth) but not higher ROE and higher firm value (measured by Tobin's Q). However, Core et al. (2006) found the results of Gompers et al. concerning ROE to be inconsistent and argued that ROA serves as a superior measurement of operating performance; they found that the G-index is significantly related to this measurement of operating performance. Later, Brown and Caylor (2006) suggested that the inconsistent results of Gompers et al. (2003) and Core et al. (2006) were not due to the choice of operating performance measures but rather because of the manner in which the G-index was constructed. They claim that the majority of the factors included in the G-index are anti-takeover measures. Hence, they developed a broader index (using 51 items) to achieve greater reliability. A number of characteristics of boards of directors were included, such as board size, number of outside directors, number of board meetings, CEO duality and board compensation. Their findings indicated that better-governed U.S. firms have higher ROE, higher ROA and higher Tobin's q. Aggarwal et al. (2010) developed an index based on 64 provisions, grouped into the following eight categories: board of directors, charter/bylaws, state incorporation, compensation, progressive practices, ownership, director education, and audits. The application of this index identified a positive relationship with firm performance, measured by Tobin's Q. However, Cheng and Wu (2006) only obtained positive results, measured in terms of stock returns, when the evidence was concentrated in large firms.

Nowadays, corporate governance indexes are generally created with reference to a number of characteristics of boards of directors. Internal factors, such as board size, number of outside directors, CEO duality, number of board meetings and CEO compensation, are most commonly used in the literature. For this reason, our index is created using only the most commonly employed variables for measuring internal corporate governance. Thus, our hypothesis is formulated as follows:

Hypothesis: Companies with high levels of corporate governance culture demonstrate superior performance. 
In addition, we test whether there are differences in the results of hypothesis when using the index or its individual variables separately. 


\section{THE STUDY}

\subsection{Sample}

We focus on a final sample of 237 non-financial companies (1,422 firm-year observations) listed on the S\&P 500 index during the period between 2004 and 2009; in particular, we focus on the period of high market volatility that occurred as a result of the financial crisis. We only select companies that were listed on both the Spencer Stuart Index report and Compustat Database during these six years; this is done in order to determine if the mentioned volatility of market values may have distorted our measurement of firms' performances, the comprehensive income. We eliminate financial firms due to their different structures and the roles of their accounts and boards of directors (Andrés et al., 2005; Sánchez-Ballesta and García-Meca, 2007; Yermack, 1996). The data is classified into eight sectors (consumer discretionary, consumer staples, energy, healthcare, industrials, technology, materials and utilities), as in the Spencer Stuart Board Index reports (see Table 1).

\section{Table 1 here}

\subsection{Measures}

\subsubsection{Corporate governance variables}

Following previous studies, we focus on aggregating corporate governance variables in an index (Beiner et al., 2006, Brown and Caylor, 2006; Campa and Donnelly, 2013; Gompers et al., 2003; Klapper and Love, 2004; and others). "The aggregate index of corporate governance remains a useful tool for continuing this line of research" (Love, 2010, p. 9). We attempt to improve upon the other indexes by being more concrete and precise; first, by selecting the most commonly used internal corporate governance variables (board size, outside directors, duality, board meetings and CEO compensation) and by excluding external variables, such as auditing committees, ownership structure, and others, that do not have any relation to board firms. Second, in order to generate a more precise index, board size and CEO compensation are related to company size. The corporate governance index is built as follows:

CG_Index $=($ BoardSize $)+($ OutsideDirectors $)+($ Duality $)+($ BoardMeetings $)+($ CEOcompensation $)$

The corporate governance variables are defined as follows:

- 'BoardSize' as the total number of directors divided by the logarithm of total equals 1 ; otherwise, it equals 0 ;

- 'OutsideDirectors' as the percentage of outside directors divided by the total number of directors. If the value of the outside directors variable is greater than 73.5 percent, then 'OutsideDirectors' equals 1; otherwise, it equals 0 ;

-'Duality' as if CEO $\neq$ Chairman, then the variable 'Duality' equals 1 ; otherwise, it equals 0 ;

- 'BoardMeetings' is equal to 1 when the number of board meetings is between four assets. If board size is between nine and twelve directors ${ }^{1}$ (both inclusive), then the variable BoardSize and ten (both inclusive); ${ }^{2}$ otherwise, it is 0 ; and

- 'CEOcompensation' represents CEO remuneration divided by the logarithm of assets. When this variable $^{2}$ is between $\$ 122,567.29$ and $\$ 318,075.74$, then the variable 'CEOcompensation' equals 1 ; otherwise, it equals 0 .

As a result, the corporate governance index can have values ranging from 0 to 5 . If a company has a value of 5 , it indicates that the firm has a good level of corporate governance culture. ${ }^{2}$

${ }^{1}$ The intervals of the variable are calculated by the mean plus or minus the standard deviation as a way of considering the majority of firms.

${ }^{2}$ Missing values of corporate governance index are set to zero (Huisman 2000). 
All of these corporate governance variables were obtained from Spencer Stuart's website, a publication of Spencer Stuart Consulting, ${ }^{3}$ while data concerning CEO duality were obtained from the firms' annual reports. ${ }^{4}$

\subsubsection{Financial performance and control variables}

The majority of previous studies have used accounting profits such as ROA, ROE or net income in order to measure firms' performance; however, due to accounting harmonization, comprehensive income value could represent the most appropriate approach to measuring profitability because it is more in accordance with the market (Arimany et al., 2011; Firescu, 2015; Kanagaretnam et al. 2009). Indeed, accounting results have greater relevance when they are associated with expected market prices (Barth et al., 2001). In this paper, we intend to determine which approach to measuring financial performance is more appropriate for our research proposal, taking into account that the specific period in question (2004-2009) experienced high levels of market volatility as a result of the financial crisis. All relevant information (including market value, total assets, ROA, ROE, net income and comprehensive income value) was obtained from the 2003 version of the Execucomp database.

We also obtained the comprehensive income values of the firms on the database from their annual reports. Comprehensive income is "the change in equity [net assets] of a business enterprise during a period from transactions and other events and circumstances from non-owner sources. It includes all changes in equity during a period except those resulting from investments by owners and distributions to owners" (SFAS No. 130, 1997). Comprehensive income is the sum of net income and other items that must bypass the income statement because they have not yet been realized; this includes items such as unrealized holding results from securities that are available for sale and gains or losses incurred as a result of foreign currency transfers. Consequently, comprehensive income is more closely related to the fluctuation of share prices and exchange rates than traditional net income, and it is thus much more in line with the market reality (Arimany et al., 2011; Firescu, 2015; Kanagaretnam et al., 2009). Bamber et al. (2010) also note that CEOs whose jobs are less secure (when measured in terms of CEO duality and the number of outside director members) and offer greater equity-based incentives (CEO Compensation) are more likely to avoid performance reporting in a performance statement than in the statement of equity. This means that, according to their own interests, managers choose different ways of presenting information.

As control variables, we use market value, sales, leverage and year dummies, as in previous studies (Beiner et al., 2006, Brown and Caylor, 2006; Campa and Donnelly, 2013; Klapper and Love, 2004; among others).

We expect a positive effect about control variables related to size (market value and sales) because previous studies indicate that the larger the company, the greater its profitability (Beiner et al., 2006; Brown and Caylor, 2006; Klapper and Love, 2004). We also expect no effect with leverage (Beiner et al., 2006).

Table 2 summarizes the descriptive variables and their sources about corporate governance variables and the control - dummy variables of sample firms (see Table 2).

Table 2 here

\subsection{Methodology}

Once the corporate governance index is built, the first hypothesis is tested, using comprehensive income (CI) as the dependent variable. We predict that companies with higher levels of corporate governance culture will have better outcomes, as expressed in the following hypothesis:

\footnotetext{
${ }^{3} \mathrm{http} / / / \mathrm{www}$. spencerstuart.com/research/articles/

${ }^{4}$ Board size and CEO compensation are deflated by asset (Hall and Weiss 1967).
} 
Hypothesis: Companies with a high level of corporate governance culture demonstrate superior performance.

In order to test this hypothesis, we estimate the following regression:

Model A: $\mathrm{CI}_{\mathrm{it}}=\beta_{\mathrm{o}}+\beta_{1}\left(\mathrm{CG}\right.$ Index $\left._{\mathrm{it}}\right)+\beta_{2}\left(\right.$ MarketValue $\left._{\mathrm{it}}\right)+\beta_{3}\left(\right.$ Sales $\left._{\mathrm{it}}\right)+\beta_{4}\left(\right.$ Leverage $\left._{\mathrm{it}}\right)+\beta_{5}\left(\right.$ year2009 $\left._{\mathrm{it}}\right)+$ $\beta_{6}\left(\right.$ year2008 $\left._{\mathrm{it}}\right)+\beta_{7}\left(\right.$ year2007 $\left._{\mathrm{it}}\right)+\beta_{8}\left(\right.$ year2006 $\left._{\mathrm{it}}\right)+\beta_{9}\left(\right.$ year2005 $\left._{\mathrm{it}}\right)+\varepsilon_{\mathrm{it}}$

Where the subscript i refers to the firm number and the subscript $t$ denotes the time period; the dependent variable $\mathrm{CI}_{\mathrm{it}}$ is the comprehensive income value for firm ${ }_{i}$ in time ${ }_{t} ; \beta_{\mathrm{o}}$ is a constant; $\beta_{1}-\beta_{9}$ are the parameters for the explanatory variables; $C G_{-}$Index $_{i t}$ refers to the corporate governance index;

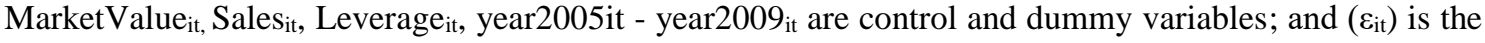
error term.

We predict a positive and significant coefficient on the interaction of CG_Index, suggesting a strong relationship between a high comprehensive income and a high level of corporate governance culture. Then, model $\mathrm{A}$ is estimated using the three alternative dependent performance variables (ROA, ROE and net income), with the control and dummy variables included on the right-hand side. We wish to test if hypothesis 1 is positive and significant regardless of the financial performance variables used.

According to the previous literature, hypothesis 1 will produce different results if an index or individual indicators of corporate governance are used. In model $1 \mathrm{~B}$, we intend to test whether the results obtained for model A remain the same when the five corporate variables, namely board size, number of outside directors, CEO duality, number of board meetings and CEO compensation, are used instead of an index. What impact does each variable have on financial performance? Will the same results be obtained using different measures of financial performance? We estimate the following regression:

Model B: $\mathrm{CI}_{\mathrm{it}}=\beta_{\mathrm{o}}+\beta_{1}\left(\right.$ BoardSize $\left._{\mathrm{it}}\right)+\beta_{2}\left(\right.$ OutsideDirectors $\left._{\mathrm{it}}\right)+\beta_{3}\left(\right.$ Duality $\left._{\mathrm{it}}\right)+\beta_{4}\left(\right.$ BoardMeetings $\left._{\mathrm{it}}\right)+$ $\beta_{5}\left(\right.$ CEOcompensation $\left._{\mathrm{it}}\right)+\quad \beta_{6}\left(\right.$ MarketValue $\left.\left._{\mathrm{it}}\right)+\right)+\quad \beta_{7}\left(\right.$ Sales $\left._{\mathrm{it}}\right)+\quad \beta_{8}\left(\right.$ Leverage $\left._{\mathrm{it}}\right)+\quad \beta_{9}\left(\right.$ year2009 $\left._{\mathrm{it}}\right)+$ $\beta_{10}\left(\right.$ year2008 $\left._{\text {it }}\right)+\beta_{11}($ year2007 $)+\varepsilon_{\text {it }}^{5}$

Model B tests a linear regression between corporate governance variables or individual indicators and comprehensive income value. The subscript $\mathrm{i}$ refers to the firm number, while the subscript $\mathrm{t}$ denotes the time period; the dependent variable $\mathrm{CI}_{\mathrm{it}}$ is the comprehensive income value for firm $\mathrm{i}$ in time $\mathrm{t}$; $\beta_{\mathrm{o}}$ is a constant; $\beta_{1}-\beta_{11}$ are the parameters for the explanatory variables; BoardSize ${ }_{i t}$, OutsideDirectors ${ }_{i t}$, Duality $_{i t}$, BoardMeetings $s_{i t}$, CEOcompensation $_{i t}$ refer to the variables belonging to the corporate governance index; MarketValue $_{i t}$, Sales it $_{\text {, Leverage }}$, year2007 $7_{i t}$ - year2009 ${ }_{i t}$ are the control and dummy variables; and $\left(\varepsilon_{\mathrm{it}}\right)$ is the error term. The control variables used are the same as in model $\mathrm{A}$.

\section{RESULTS AND DISCUSSION}

\subsection{Descriptive statistics and correlation analysis}

The final sample consisted of 237 companies (1,422 firm-year observations) that had been listed on the S\&P 500 index during the period between 2004 and 2009. Table 3 provides the descriptive statistics of all of the variables considered in this study: the corporate governance index, the five corporate governance variables (board size, number of outside directors, CEO duality, board meetings and CEO compensation), the four financial performance measures (ROA, ROE, comprehensive income and net income) and the control variables (market value, leverage and sales). On average, all of the variables considered in this study had a positive value (see Table 3 ).

Table 3 here

${ }^{5}$ There is no data for CEO composition in years 2005and 2006. 
The corporate governance index mean is 3.05 out of 5 , with a standard deviation of 0.94 . Thus, the range of corporate governance index in our sample is between 2.11 and 3.99. This means that, on average, the firms in our sample demonstrate a high level of corporate governance culture. The fact that the sample firms are listed on the S\&P 500 index is likely a guarantee of high levels of corporate governance. Other studies use different corporate governance variables in the index, but all of them obtain the same results: higher values on corporate governance indexes (i.e. Beiner et al., 2006, Brown and Caylor, 2006; Campa and Donnelly, 2013; Gompers et al., 2003; Klapper and Love, 2004; among others).

When analysing the corporate governance variables of the index separately, our results indicate that the median of the board size, the variable that is most frequently used in the literature to measure the effectiveness of corporate governance (Huse, 2000), has 10.63 members. In our research, the ideal number of directors is found to be between 8 and 12; our results are thus in line with the ranges determined in other studies, such as those of Campa and Donnelly (2013), Jensen (1993) and Lipton and Lorsch (1992), among others. The percentage of outside directors, considered to be "the crucial corporate governance mechanism for monitoring managers" (Bhagat et al., 2008), has a significant relationship to board size, as was the case in other studies (i.e.; Dalton et al., 2007; Dalton and Dalton, 2011; Fogel and Geiger, 2007). The ideal average ratio of outside to total directors is upper 73.58 percent, as was found in previous studies (Matolcsy et al., 2004).

According to the categorical variable "duality", in our sample there were 1,201 firm-year observations that the CEO and the president were the same person, constituting 84.5 percent of the total sample. Our sample is biased in terms of this variable, but this is a common situation in real life.

The number of meetings in our sample was, on average, 8 per year, with a high range of between 4.88 and 11.12. This result is in line with other studies, such as those of Vafeas, (1999), who found a mean of 7 meetings per year and a standard deviation of 2.66; Adams and Mehran (2008), with a mean of 8.48 meetings and a standard deviation of 3.30; and Brick and Chidambaran (2010), with a mean of 7.2 meetings per year and a deviation of 3.05 .

According to the board remuneration variable, our values were approximately between $\$ 22,567.29$ and $\$ 318,075.74$, showing a high dispersion. This also occurs with the control variable of market value: Its mean is $\$ 26,762$ million, with a standard deviation of $\$ 46,941$ million. The same high dispersion is demonstrated by the sales variable, with a mean of $\$ 26,937$ and a standard deviation of $\$ 79,717.43$. The leverage variable interval is between 0.78 and 2.64 .

Table 4 depicts the correlation matrix. There is a positive and high correlation between board size and outside directors (86 percent), in line with the findings of Matolcsy et al. (2004). This means that there is a high probability of having outside directors in large-sized boards, although this is not dependent on firm size. Logically, there is also a positive correlation between ROA and ROE (71 percent), as ROA conditions ROE. As net income is an element of comprehensive income, they are also highly correlated (93 percent). Finally, market value is also correlated with net income ( 89 percent), comprehensive income ( 85 percent) and with firm size ( 63 percent). This means that the higher the market value of a firm, the larger its size and the higher its financial performance (see Table 4).

Table 4 here

\subsection{Regression analysis}

The regression analyses show the results of our models between corporate governance (disaggregating variables and aggregated in an index) and comprehensive income value.

In model $\mathrm{A}$, a linear relationship between the corporate governance index and comprehensive income value is tested. Table 5 presents the results of the regression. The null hypothesis could not be rejected at 
a significance level of 10 percent ( $\mathrm{p}$-value=0.077), so the level of corporate governance culture has a positive impact on firm performance as measured by comprehensive income value. These results are in line with previous studies that have used other corporate governance indexes to obtain significant and positive values (Beiner et al., 2006, Brown and Caylor, 2006; Campa and Donnelly, 2013; Gompers et al., 2003; Klapper and Love, 2004; among others). The control variable, the market value, a measurement of firm value, is positive and significant $(0.000 \mathrm{p}$ value). This means that large companies demonstrate greater profitability, again in line with the findings of previous studies (Beiner et al., 2006; Brown and Caylor, 2006; Klapper and Love, 2004; among others) (see Table 5).

Table 5 here

Regarding the year dummies, only $\beta_{6}(-835.5)$ had a significant impact (p-value: 0.000$)$, which indicates that, in 2008, net income was, on average, approximately $\$ 835$ million lower than in 2004 . This is obviously due to the negative effects of the economic crisis.

The remaining control variables in model A (sales, leverage and year dummies) have no significant impact on firm performance. This means that revenue and debt structures do not affect the relationship between level of corporate governance culture and profitability.

In model B (see Table 6), the corporate governance index is disaggregated in order to analyze how the five corporate governance variables impact financial performance. The results indicate that outside directors and board meetings cannot be rejected at a significance level of five percent (with p-values of 0.017 and 0.014, respectively). Several studies support these results (Jackling and Johl, 2009; Luan and Tang, 2007; McDonald et al., 2008; O'Connell and Cramer, 2010; Peng, 2004; Rhoades et al., 2001). Having a higher percentage of outside directors and a lower number of board meetings has, on average, a positive impact on a firm's performance. It is true that external directors are more likely to manage firms in a professional manner than dependent directors, as the former tend to apply their management knowledge and only take into account the firm's best interests. Moreover, holding meetings leads to high costs for firms, so, if companies hold few meetings, they may be more efficient, which could have a positive impact on their performance. Indeed, new communication technologies and the Internet are improving the relationships between firms and their board members without the need for more board meetings (except when strictly necessary). Board size, duality and CEO compensation have no significant impact on firm performance in terms of the remaining variables (sales, leverage and year dummies, except year 2008). (see Table 6)

Table 6 here

\subsection{Robustness tests}

The accounting measures (ROA, ROE and net income) described below are used to test our robustness models, leading to quite different results. All of the models are estimated using the three alternative dependent performance variables (ROA, ROE and net income), with the control and dummy variables included on the right-hand side. Three regression models, using ROA, ROE and net income as dependent variables, are set up in order to determine the importance of these measurements of financial performance. The results are different, as seen below. Market value, sales, leverage and year dummies are included amongst the set of control variables in these models.

The corporate governance index is positive with net income, negative with ROA and non-significant with ROE. This diversity of the results obtained in our study are in line with those of other authors, one group of which argues that "most governance studies are fraught with a variety of limitations, including inconsistent measurement of performance, differing governance standards worldwide and the additional impact of contextual factors" (Dalton et al., 1998).

The results obtained depend on the measure of profitability used, as shown in Table 7, below.

Table 7 here 


\section{CONCLUSIONS AND PRACTICAL IMPLICATIONS}

The objective of this paper was to analyze the effect of corporate governance strategies on a measure of firms' financial performance, the comprehensive income. The previous literature indicates that the effects of corporate governance on financial performance are not conclusive, but, in the majority of cases, the results are significant and positive. Our corporate governance index is more concrete and precise than others because we selected the most intrinsic corporate governance variables and excluded external variables, such as auditing committees, ownership structure, and others, that do not have any relationship to board firms. The process by which financial performance is measured is also more robust because it has an impact on value creation.

Our results support the notion that a potential method by which firms' boards could achieve greater profitability or otherwise enhance firms' value is the application of superior corporate governance strategies. In this research, this was demonstrated using a sample of 237 firms listed on the S\&P 500 Index during the years between 2004 and 2009. This means that corporate governance practices are considered to be a source of competitive advantage for firms that incorporate these practices in their core business strategies (Gómez and Ucieda, 2013).

When we disaggregated the corporate governance index, the results indicated a positive correlation between the percentage of outside directors and financial performance and a negative one between the number of board meetings and financial performance. However, no significant correlations were found between board size, duality, CEO compensation and financial performance. This finding is relevant for boards of directors because they should be aware that a higher number of outside directors and lower numbers of board meetings may result in superior financial performance and increased firm value. Additionally, stakeholders may ask the management of firms to adopt corporate governance practices, as doing so will have positive effects on comprehensive income, and, consequently, firms' value creation.

This study has some limitations, which may also represent avenues for future research. First, the small size of the sample and the limited period of time considered may also explain the absence of support for some of our hypotheses; no significant correlations were found between board size, duality, CEO compensation and financial performance. Second, our corporate governance index could be created with a greater number of, or different, variables; we used a narrow scope, focusing on the corporate governance variables commonly used in research in this field.

Future studies are required in order to expand upon the scope of this research; for example, future work may consider how transparency and corporate governance variables impact firms' performance or how a firm's internal governance structure impacts its financial performance, as it can be in Spain, such as Rodriguez-Fernandez (2014). Our study contributes to the extant literature in the area of corporate governance and suggests other possible approaches to measuring a firm's performance. Companies nowadays could create a firm's value better than more profitability goals. 